\title{
IgA nephropathy associated with thalassemia: a case report
}

\author{
Jun $\mathrm{Ni}^{1 *}$, Caifeng Zhu', Xiaoqiu $\mathrm{Ni}^{2}$ and Jiazhen $\mathrm{Yin}^{1}$
}

\begin{abstract}
Background: Thalassemia is a group of hereditary diseases characterized by a common recessive monogenic hematological disorder, presenting a significant public health concern in the developing countries. Recent studies have identified the renal effects of thalassemia syndrome. Chronic hypoxia, long-term anemia, iron overload, and iron chelators are the major causes of renal tubular dysfunction and glomerular filtration abnormalities, while glomerulonephritis is not considered a major cause of abnormal urinalysis.

Case presentation: We report a case of a 38-year-old female patient with immunoglobulin A (IgA) nephropathy accompanied by anemia who was misdiagnosed initially, but was diagnosed with alpha-thalassemia after gene tests. We administered a combination of oral prednisolone, leflunomide, and angiotensin receptor blockers as well as folic acid and mecobalamin. During the follow-up, her proteinuria was significantly reduced, and her anemia was improved.

Conclusions: The possibility of occurrence of thalassemia should be considered in IgA nephropathy complicated with refractory anemia, especially in high-incidence areas of the disease.
\end{abstract}

Keywords: a-Thalassemia, IgA nephropathy, Renal complications

\section{Background}

Thalassemia refers to a group of hereditary hemolytic anemias, wherein mutations or deletions of the globin gene lead to various degrees of inhibition in $\alpha$ or $\beta$ globin synthesis. The clinical manifestations are correlated with the severity of the disease. The manifestations primarily include anemia, jaundice, and hepatosplenomegaly. Population mobility and migration have allowed the disease to become increasingly common. The prevalence of $\alpha$-thalassemia and $\beta$-thalassemia in China was 7.88 and $2.21 \%$, respectively and the diseases were mainly distributed in the southern China [1]. Recent studies have identified the proximal tubular damage and glomerular filtration abnormalities in thalassemia.

\footnotetext{
* Correspondence: junni555@yahoo.com

${ }^{1}$ The Department of Nephrology (Key laboratory of management of kidney disease in Zhejiang province), Hangzhou Hospital of Traditional Chinese Medicine, Hangzhou, Zhejiang, P. R. China

Full list of author information is available at the end of the article
}

However, to the best of our knowledge, immunoglobulin A (IgA) nephropathy (IgAN) has rarely been reported in patients with thalassemia. The present report describes the first case of IgAN that is associated with $\alpha$ thalassemia.

\section{Case presentation}

A 38-year-old female was admitted to our center with a complaint of abnormal urine tests. She was diagnosed with chronic nephritis syndrome 10 years ago, but did not receive appropriate medical care during this period. The patient also complained of menorrhagia with unexplained anemia. Physical examination revealed no positive signs such as bilateral lower limb edema or hepatosplenomegaly. Urinalysis revealed proteinuria $(2+)$, blood (3+), and more than $75 \%$ the dysmorphic red blood corpuscles. The protein content was $0.71 \mathrm{~g}$ in $24-\mathrm{h}$ urine analysis. The urinary $\mathrm{N}$-acetyl- $\beta$-D-glucosaminidase was $11.14 \mathrm{U} / \mathrm{g} \cdot \mathrm{Cr}$, and urinary $\alpha 1$ microglobulin

(c) The Author(s). 2020 Open Access This article is licensed under a Creative Commons Attribution 4.0 International License, which permits use, sharing, adaptation, distribution and reproduction in any medium or format, as long as you give appropriate credit to the original author(s) and the source, provide a link to the Creative Commons licence, and indicate if changes were made. The images or other third party material in this article are included in the article's Creative Commons licence, unless indicated otherwise in a credit line to the material. If material is not included in the article's Creative Commons licence and your intended use is not permitted by statutory regulation or exceeds the permitted use, you will need to obtain permission directly from the copyright holder. To view a copy of this licence, visit http://creativecommons.org/licenses/by/4.0/ The Creative Commons Public Domain Dedication waiver (http://creativecommons.org/publicdomain/zero/1.0/) applies to the data made available in this article, unless otherwise stated in a credit line to the data. 
was $12.6 \mathrm{mg} / \mathrm{L}$. In additional renal function tests, creatinine clearance rate was $96.1 \mathrm{ml} / \mathrm{min}$, glomerular filtration rate (GFR) was $93.1 \mathrm{ml} / \mathrm{min}$; and serum creatinine was $71 \mu \mathrm{mol} / \mathrm{L}$. The albumin content was $34.5 \mathrm{~g} / \mathrm{L}$, and the results of thyroid function tests were within the normal ranges. Tests for anti-neutrophil cytoplasmic antibodies, anti-nuclear antibodies and anti-double-stranded DNA antibodies were negative. No viral markers of hepatitis were detectable, and all the antibodies were negative except the surface antibodies. Levels of serum IgA and complement component C3 were also normal. Ferritin level was $44.1 \mathrm{ng} / \mathrm{mL}$. Complete blood tests revealed microcytic hypochromic anemia. Hemoglobin (Hb) was $84 \mathrm{~g} / \mathrm{L}$, mean corpuscular volume was $69 \mathrm{fL}$, and mean corpuscular $\mathrm{Hb}$ was $22 \mathrm{pg}$. Ultrasonography results of kidney were normal. Results of renal biopsy showed that 15 glomeruli were detected by light microscopy and one of them exhibited fibrocellular crescents. Renal tubules displayed localized atrophy, and inflammatory cell infiltration as well as fibrosis in the interstitium. Arteries and arterioles were unremarkable. Immunofluorescent analysis revealed diffuse IgA $(3+)$ and C3 (2+) staining were present in several mesangial areas. Based on these results, the patient was diagnosed with IgAN accompanied by iron deficiency anemia. We treated the patient with a combination of oral prednisolone, leflunomide, and angiotensin receptor blockers (ARBs). In addition, polysaccharide-iron complex was also administered. A complete remission of proteinuria was observed, and hematuria was also relieved. However, $\mathrm{Hb}$ was constantly under the normal reference range, which could not be explained by the iron deficiency anemia. In 2016, the patient was diagnosed with $\alpha$ thalassemia based on the results of our genetic tests showing the deletion of --SEA gene. Serum $\mathrm{HbF}$ and HbA2 were elevated to 2.47 and $3.04 \%$, respectively. During the 3-year follow-up, a significant improvement in anemia was observed following the treatment consisting of a small dose of ARB with folic acid and mecobalamin administration. Laboratory tests in March 2019 showed that $\mathrm{Hb}$ levels were elevated to $157 \mathrm{~g} / \mathrm{L}$. Urine occult blood was $2+$, 24 -h proteinuria was reduced to $0.08 \mathrm{~g}$, and serum creatinine and albumin were normal.

\section{Discussion and conclusions}

Thalassemia is a common inherited disease of hemoglobin synthesis worldwide. Patients with thalassemia have a wide spectrum of clinical phenotypes depending on their respective genotype characteristics. Some patients with thalassemia may not have any clinical symptoms, leading to misdiagnosis. Patients with thalassemia major, the most severe type, usually require regular blood transfusions for survival and some patients even die in utero or shortly after birth. The mortality of thalassemia is considerable, particularly among children [2].

Although clinical manifestations of thalassemia can be accompanied by multisystem complications including cardiopulmonary dysfunction and endocrine organ disease, kidney involvement has received less attention. Previous clinical studies have identified thalassemiaassociated proximal tubular dysfunction and abnormalities in GFR [3], which have been confirmed in animal models as well [4]. Ahmadzadeh et al. [5] reported that 140 Iranian children with $\beta$-thalassemia had elevated levels of urinary $\mathrm{N}$-acetyl- $\beta$-D-glucosaminidase and ferritin, suggesting tubular dysfunction. Moreover, proteinuria and microscopic hematuria were also observed in children with $\beta$-thalassemia, suggesting the probable association of glomerular disease with thalassemia.

The pathogenesis of kidney dysfunction among patients with thalassemia may involve chronic hypoxia that causes proximal tubular cells dysfunction and interstitial fibrosis with consequent renal damage. Anemia induces renal hemodynamic changes in the presence of other risk factors [6, 7]. Nickavar [8] reported that almost $20 \%$ of the patients with $\beta$-thalassemia minor had relatively low urine osmolality, suggesting tubular dysfunction. In the present case, the patient also showed elevated urinary $\mathrm{N}$-acetyl- $\beta$-D-glucosaminidase and $\alpha 1$ microglobulin levels. In patients who receive regular transfusion, the destruction of glomerular filtration barrier is also attributed to iron overload secondary to regular blood transfusion, resulting in an increase of oxidative stress and direct cytotoxicity, which in turn leads to a decline in the ability of the kidneys to clear immune complexes (ICs) [9]. The use of specific iron chelators may also lead to kidney damage. Some clinical reports have found that the occurrence of proteinuria in thalassemia is correlated with iron toxicity [10]. Microscopic hematuria is often observed in thalassemia patients, which may be related to tubular dysfunction induced by hyperuricosuria, hypercalciuria, iron overload, or deferoxamine. Glomerulonephritis is not considered as a major cause of microscopic hematuria.

Thalassemia associated with IgAN is relatively rare. In 1994, Harada [11] reported a case of a beta-thalassemia patient with microscopic hematuria, which was later diagnosed with IgAN. Jung Hyun Kang et al. [12] reported a case of a beta-thalassemia minor patient who did not receive any specific treatment for anemia. During the follow-up, the patient exhibited overt microscopic hematuria and proteinuria with elevated serum IgA levels and was diagnosed with IgAN after renal biopsy. In 2016, Mrabet [13] also reported a case of a betathalassemia minor patient associated with IgAN who showed persistent microscopic hematuria and new-onset overt proteinuria. 
ICs are considered important pathogenic factors of IgAN. Factors affecting the deposition of ICs in glomeruli are mainly the one associated with the ability of the body to clear ICs. The elimination of ICs in human circulation is mostly accomplished by erythrocytes through immune adhesion and phagocytosis. When erythrocyte immune function is impaired or the complementdependent clearance mechanism is affected by immune deficiency, the activity of complement receptor type 1 on erythrocyte membrane is decreased. Its ability of recognizing, adhering to, and clearing ICs is also decreased [14]. Therefore, ICs in the circulation are abnormally deposited in the mesangial area while being filtered by the glomerulus. This results in mesangial cell proliferative response, which constitutes the histopathological basis of IgAN. Thus, in patients with thalassemia, impaired elimination of circulating ICs possibly leads to IgAN.

The present report is the first one describing IgAN associated with $\alpha$-thalassemia. The occurrence of IgAN in this case may be related to the impaired clearance of circulating ICs caused by thalassemia. However, the possibility of a concomitant existence of these two diseases could not be excluded, as both are common diseases in China. The patient has been followed up for more than 7 years and her condition is relatively stable under the current treatment. While treating with patients having urinary abnormalities combined with anemia, especially in cases wherein the renal function is insufficient, thalassemia is more likely to be misdiagnosed or missed, even in high incidence areas of the disease.

\section{Abbreviations \\ IgAN: Immunoglobulin A nephropathy; GFR: Glomerular filtration rate; Hb: Hemoglobin; ARBs: Angiotensin receptor blockers; ICs: Immune complexes}

\section{Authors' contributions}

JN was responsible for designing and data analysis and was a major contributor in writing the manuscript. CZ participated in the treatment as primary physician and contributed to the collection and analysis of patient's data. XN assisted in editing the manuscript. JY performed the pathological interpretation of the renal tissue. All authors have read and approved the manuscript.

\section{Funding}

There was no funding support for this article.

\section{Availability of data and materials}

Data regarding this study were obtained from clinical charts stored in the physician office records of Hangzhou Hospital of Traditional Chinese Medicine, therefore, cannot be shared. Any reasonable request to access the data must be approved before the data can be released.

\section{Ethics approval and consent to participate}

Not applicable.

\section{Consent for publication}

Written informed consent was obtained from the patient prior to the use of her data for publication.

\section{Competing interests}

The authors declared that they have no competing interests.

\section{Author details}

${ }^{1}$ The Department of Nephrology (Key laboratory of management of kidney disease in Zhejiang province), Hangzhou Hospital of Traditional Chinese Medicine, Hangzhou, Zhejiang, P. R. China. ${ }^{2}$ Zhejiang Chinese Medical University, Hangzhou, Zhejiang, P. R. China.

Received: 3 September 2019 Accepted: 8 May 2020

Published online: 14 May 2020

\section{References}

1. Lai K, Huang G, Su L, et al. The prevalence of thalassemia in mainland China: evidence from epidemiological surveys [J]. Sci Rep. 2017;7(1):920.

2. Kassebaum NJ, Jasrasaria R, Naghavi M, et al. A systematic analysis of global anemia burden from 1990 to 2010[J]. Blood. 2014;123(5):615-24.

3. Tantawy AA, El Bablawy N, Adly AA, et al. Early predictors of renal dysfunction in Egyptian patients with beta-thalassemia major and intermedia. Mediterr J Hematol Infect Dis. 2014;6:e2014057.

4. Zhou XJ, Laszik Z, Wang XQ, et al. Association of renal injury with increased oxygen free radical activity and altered nitricoxide metabolism in chronic experimental hemosiderosis. Lab Investig. 2000;80(12):1905-14.

5. Ahmadzadeh A, Jalali A, Assar S, et al. Renal tubular dysfunction in pediatric patients with beta-thalassemia major [J]. Saudi J Kidney Dis Transpl. 2011; 22(3):497-500

6. Mallat NS, Mallat SG, Musallam KM, et al. Potential mechanisms for renal damage in beta-thalassemia [J]. J Nephrol. 2013;26(5):821-8.

7. Musallam KM, Taher AT. Mechanisms of renal disease in $\beta$-thalassemia [J]. J Am Soc Nephrol. 2012;23(8):1299-302.

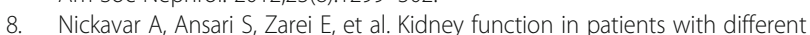
variants of Beta-thalassemia [J]. Iran J Kidney Dis. 2017;11(2):132-7.

9. Quinn $C T$, Johnson VL, Kim HY, et al. Renal dysfunction in patients with thalassemia [J]. Br J Haematol. 2011;153(1):111-7.

10. Ziyadeh FN, Musallam KM, Mallat NS, et al. Glomerular hyperfiltration and proteinuria in transfusion-independent patients with $\beta$-thalassemia intermedia [J]. Nephron Clinical Practice. 2012;121(3-4):c136-43.

11. Harada T, Ozono Y, Miyazaki M, et al. Association of IgA nephropathy and beta-thalassemia [J]. Clin Nephrol. 1994;41(3):181-2.

12. Kang JH, Park BR, Kim KS, et al. Beta-thalassemia minor is associated with IgA nephropathy [J]. Ann Lab Med. 2013;33(2):153-5.

13. Mrabet $S$, Bourkhis $L$, Abdelkarim SB, et al. IgA nephropathy, $\beta$ thalassemia minor, psychosis and deafness: a new syndrome [J]. J Nephrol Ther. 2016; 6(237):2161-0959.1000237.

14. Anderson HL, Brodsky IE, Mangalmurti NS. The evolving erythrocyte: red blood cells as modulators of innate immunity [J]. J Immunol. 2018;201(5): $1343-51$.

\section{Publisher's Note}

Springer Nature remains neutral with regard to jurisdictional claims in published maps and institutional affiliations. 